\title{
Pi Glutathione S-Transferase Measurement
}

National Cancer Institute

\section{Source}

National Cancer Institute. Pi Glutathione S-Transferase Measurement. NCI Thesaurus.

Code C80203.

The determination of the amount of Piglutathione-s-transferase present in a sample. 